\title{
A MÁSCARA DA REDE E O SUJEITO AUTOMÁTICO DE SUA INTERFACE
}

\section{I}

\author{
Irlim Corrêa de Lima Júnior \\ Doutorando em filosofia (PUC-RIO) \\ Bolsista Capes
}

Resumo: Fazendo confluírem as reflexões de Marx sobre a natureza e o funcionamento do capital com os prognósticos de Deleuze acerca da sociedade de controle, a partir da problemática levantada por Julian Assange, em seu livro Cypherpunks, quanto ao contínuo controle e monitoramento do fluxo informacional da internet, a intenção deste trabalho consiste em refletir sobre como a internet, sob a égide do fenômeno contemporâneo do controle, realiza-se no mundo atual como a interface de controle e poder à disposição da lógica do capital.

\footnotetext{
Não há necessidade de ficção científica para conceber um mecanismo de controle que forneça a cada instante a posição de um elemento em meio aberto, animal numa reserva, homem numa empresa (coleira eletrônica). Félix Guattari imaginava uma cidade onde cada um pudesse deixar seu apartamento, sua rua, seu bairro, graças ao seu cartão eletrônico, que removeria qualquer barreira; mas, do mesmo modo, o cartão poderia ser rejeitado tal dia, ou entre tais horas; o que conta não é a barreira, mas o computador que localiza a posição de cada um, lícita ou ilícita, e opera uma modulação universal.

Gilles Deleuze, Post-Scriptum sobre as sociedades de controle
}

O excerto que elegemos como epígrafe integra um dos mais inquietantes e agudos prognósticos de Deleuze acerca das relações de poder que, tácita ou explicitamente, se encontram em processo de constituição e expansão no mundo contemporâneo. Sob o paradigma do que nomeou como sociedade de controle, um novo regime de dominação se impõe ao mundo da globalização, uma forma hecatônquira e high-tech do leviatã.

Deleuze, de fato, adverte que a complexidade desse monstro é difícil de ser apreendida: ela é como uma sinuosa serpente, contendo inúmeros anéis. Enquanto 
um corpo complexo e múltiplo, esse monstro insinua-se realmente ambíguo, podendo pender para o lado de uma dominação irrefreável ou, ao contrário, para o de uma resistência inexterminável. O que interessa, porém, a Deleuze mais especificamente passa longe de pretender efetuar um auspício sobre o futuro, mas de apreender as linhas de força que se conflagram e se subtraem pelos territórios da atualidade, constrangendo-a em suas demarcações e ali confinando suas potencialidades de transmigrarem para outras margens e efetuarem em sentido radicalmente inverso cortes e transgressões. Deleuze tem toda razão quando diz ser dispensável a ficção científica para conceber essa ideia. Essa aparente utopia tem lugar justamente na distopia do nosso presente.

Atualmente a internet e os mais variados gadgets, pelos quais podemos estar constantemente conectados, tornaram os dispositivos conceituais de Deleuze para a sociedade de controle uma realidade altamente presente e, muitas vezes, encarada de forma trivial, pois fazem parte do nosso cotidiano e dos nossos afazeres, configurando-se como um dos elementos mais centrais do nosso modo de vida, senão o próprio centro nevrálgico do mundo contemporâneo. A web é a interface das transações e das relações do mundo contemporâneo, com toda sua trama entremeada de complexidade e de simultaneidade capaz de conectar pessoas ao redor do globo terrestre. Por permitir entre elas a interação e a comunicação instantâneas com uma multiplicidade de informações e subjetividades que estão conectadas de modo descentralizado, em rede e livre de fronteiras, a internet representa, entre outras coisas, um espaço midiático que rompe com a unilateralidade das mídias convencionais, franqueando suas amplitudes para as múltiplas interseções, intervenções e ações diretas, espontâneas, singulares, escapando aos centros de sanções e de poder tradicionais e estáveis. Como espaço por excelência da capacidade de comunicar as múltiplas dimensões singulares dos 
indivíduos e fazê-las interagirem, a web é a mídia que faz acontecer um compartilhamento livre e democrático de ideias. Seu potencial político para transformar esse compartilhamento em capacidade de articulação de ações e estratégias políticas efetivas no mundo físico tem se mostrado cada vez maior nos últimos anos.

Mas se nos últimos anos nos deparamos com movimentos em rede de militância democrática contra os aparelhos mais diversos do poder centralizador (o capital financeiro, o Estado, corporações multinacionais, instituições políticas, sociais, jurídicas...), também vimos ocorrerem casos que expuseram a disseminação na e através da internet do que Deleuze denominara sociedade de controle. Dentre os inúmeros casos de perseguição pessoal ou generalizada contra ativistas pela liberdade das mídias e hackers, constam, dentre os mais famosos, de Chelsea Manning, Julian Assange e Edward Snowden. O último, refugiado provisoriamente na Rússia, expôs o sistema de vigilância global instaurado pelas agências de inteligência americanas (NSA, CIA, FBI), em cooperação com empresas privadas de tecnologia de informação, as quais, nem que seja parcialmente, possuem acesso às informações coletadas. Todo conteúdo que atravessa a internet é, pela mediação de dispositivos e ferramentas tecnológicos altamente avançados, filtrado, catalogado, organizado e armazenado pelo governo americano. Também os demais governos do mundo inteiro realizam essa vigilância, em escala de acordo com o seu aparato tecnológico. Não somente eles: também empresas, instituições financeiras, bancos, corporações... Se há uma multiplicidade de ações e expressões de ideias democráticas e singulares surgindo e transitando pela rede, existe também no meio dela como se fosse uma invisível trama que captura e controla suas flutuações, seus fluxos e modulações. Por detrás da expressividade singular, insinua-se a vigilância universal dos poderes centralizados. 
Essa vigilância é o que Assange, em seu livro Cypherpunks, chama de uma distopia transnacional pós-moderna. Com efeito ele escreve: "A internet, nossa maior ferramenta de emancipação, está sendo transformada no mais perigoso facilitador do totalitarismo que já vimos. A internet é uma ameaça à civilização humana." ${ }^{1} \mathrm{O}$ mundo inteiro, na medida em que cada vez mais interage e realiza-se dentro da e por mediação da internet, encontra-se a galope para essa distopia. O tom do livro, sobretudo nas páginas iniciais, é sombrio e apocalíptico, claro, mas nem por isso menos realista. O que há de pós-moderno nesse totalitarismo é o fato de não se reger sob o paradigma da sociedade disciplinar, que caracterizou o exercício de poder ao longo da modernidade, segundo as vastas análises de Foucault, mas sim que o totalitário entremeia-se pelo colorido das múltiplas formas e expressões das individualidades. Assange, seguindo no seu alerta, aponta para a problemática natureza física da internet, comprometida com os poderes vigentes:
A natureza platônica da internet, das ideias e dos fluxos de informações, é degradada por suas origens físicas. Ela se fundamenta em cabos de fibra óptica que cruzam oceanos, satélites girando sobre nossa cabeça, servidores abrigados em edifícios, de Nova York a Nairóbi. (...) O novo mundo da internet, abstraído do velho mundo dos átomos concretos, sonhava com a independência. No entanto, os Estados e seus aliados se adiantaram para tomar o controle do nosso novo mundo - controlando suas bases físicas. ${ }^{2}$

Assange vê no conluio entre os Estados e aliados uma forma de controle, por meio da interceptação e da vigilância, sobre o fluxo das informações que tramitam na internet. Garantindo poder sobre o substrato material da internet e ampliando a capacidade de criar ferramentas para interceptar as informações, as forças que concentram poder se apropriam, de acordo com seus interesses, da essência do nosso mundo, a informação, e das singularidades que compartilhamos nele. Esse 
neototalitarismo se caracterizaria pela sua capacidade de flutuar do mundo físico para o virtual e vice-versa, das informações e perfis para a vida, os acontecimentos, os corpos e as individualidades, tudo isso sem se deixar perceber, subtraindo-se aos olhares e perspectivas e, por essa razão, potencializando sua ação de vigilância.

Mas, afinal, é possível que esses Estados e aliados não sejam o poder primeiro e derradeiro por detrás desse processo de supremacia global por meio da vigilância? Ou melhor, que não respondam primariamente pela força motriz do processo, sendo, na verdade, fenômenos derivados - ainda que autoconstitutivos no interior do processo? Slavoj Žižek, confrontando os problemas da determinação em última instância e - por que não? - por princípio da economia sobre os fenômenos sociais em geral, analisa:

(...) a economia nunca é diretamente apresentada como um agente causal atual, sua presença é puramente virtual, é a "pseudocausa" social, mas, precisamente como tal, causa absoluta, não relacional, ausente, algo que nunca está "em seu próprio lugar": eis por que o 'econômico', propriamente falando, nunca é dado, mas designa uma virtualidade diferencial a ser interpretada, sempre recoberta por suas formas de atualização. ${ }^{3}$

O plano da pseudocausalidade econômica atua sobre as formas de atualização, quer dizer, sobre a ontologia do real de maneira remota, mediata e virtual. Significa isso que nenhuma ocorrência é derivada de uma causa puramente econômica, porquanto sempre envolva uma gama de relações, interesses e interferências que são de outra ordem, mais concretas e imediatas, pertencendo ao mundo da vida. A economia como um agente atual regulador de todas as coisas seria, com efeito, uma absoluta abstração, no que Marx nunca incorreu. A economia não tem uma vida absolutamente autônoma, mas sua capacidade de movimentar o real imiscui-se ao processo de sua produção, inserindo-se como seu fator central.

3 ZIZEK, Slavoj. Menos que nada: Hegel e a sombra do materialismo dialético, p. 341. 
Pseudocausa porque justamente o conceito de causalidade não pode ser empregado aqui, uma vez eliminada a noção de agente e a noção de contiguidade relacional. Uma espécie de fenda pré-ontológica separa a ontologia do real e a virtualidade do campo de efeitos remotamente interferenciais da economia. O raio de efeito é o vácuo e o rasgo diferenciais que os separam, mas que nem por isso deixa de exercer um poder de atração ainda mais determinante. Em decorrência disso, a virtualidade econômica sobreassume a condição de causa absoluta das formas do real: justamente como ausência e controle.

O motor dessa máquina de causalidade virtual é, a saber, a própria lógica de funcionamento do capital, cujas leis e mecanismos Marx se empenhou em deslindar. Marx sublinha diversas vezes que a economia capitalista não é um simples fruto da livre iniciativa e vontade dos empreendedores individuais que se projetam ao mesmo tempo em concorrência à produção e à especulação financeira. É evidente que sem as vidas e as motivações individuais não há capitalismo. As singularidades, nesse caso, são elementos da subsistência do capitalismo, mas a subsistência, conquanto que seja o substrato, está longe de manifestar-se sendo produção substancial da lógica que rege o capital e, por extensão, as livres iniciativas. Marx percebe a diferença que existe entre os planos da realidade e da lógica imanente e material do capital. Enquanto as individualidades visam, de acordo com seus interesses, a produção de mercadorias e ganhar dinheiro, a lógica interna do capital rege-se independente de suas vontades como produção contínua de valor. Sob esse prisma, o valor atua como sujeito automático do processo de produção e reprodução do capital e, além disso, acrescentamos com base em Žižek, a causa absoluta e fundamental do metabolismo social da vida humana, pois as vidas singulares acabam por serem tragadas como matéria e energia para a produção de mais-valor. Em $O$ Capital, Marx escreve: 
(...) mercadoria e dinheiro funcionam apenas como modos diversos de existência do próprio valor: o dinheiro como seu modo de existência universal, a mercadoria como seu modo existência particular, por assim dizer, disfarçado. O valor passa constantemente de uma forma a outra, sem se perder nesse movimento, e, com isso, transforma-se no sujeito automático do processo. ${ }^{4}$

Na relação contínua de intercâmbio entre mercadoria e dinheiro, o universal a todo instante é convertido no particular e vice-versa. É no processo de produção das mercadorias e de obtenção do dinheiro que se exerce controle do capital sobre os corpos, as vontades, as idiossincrasias, as identidades, as vidas, pois fazem deles um ininterrupto jogo em que quem ganha é acima de tudo a lógica do sistema que se replica e difunde. A máquina que envolve a vida humana, seja a dos burgueses ou dos proletariados, e a põe para funcionar é a lógica de produção e circulação desmedida do valor. Como fundamento do processo, o valor transforma-se em sujeito automático, que, nas palavras de Žižek, consiste num "oximoro que une subjetividade viva e automatismo morto (...), um processo de subjetiva automediação e pôr retroativo de pressupostos". ${ }^{5} \mathrm{O}$ valor, em outras palavras, assume uma vida própria, mas sua vida é a de um autômato, a de uma máquina cega de produção que captura os mais variados fatores da vida e deles se apropria para a intensificação e a extensão da reprodução do próprio valor, inclusive redesenhando seus antecedentes físicos e históricos em vista de que sirvam agora e retroativamente como a elementos de sua própria teleologia. O campo de virtualidade do valor é capaz de flutuar pelas múltiplas dimensões da temporalidade, mediando remotamente as vidas e sobredeterminando-as projetiva ou retroativamente, na intenção cega e automática de servir à sua autorreprodutividade.

Uma reflexão de Marx, que consta como apêndice nos Manuscritos econômico-filosóficos acerca do dinheiro e das relações que através dele são

MARX, Karl. O capital: livro I, p. 203.

ZIZEK, Slavoj. Menos que nada: Hegel e a sombra do materialismo dialético, p. 92. 
instauradas nos faz refletir sobre a natureza e o impacto dessa invisível automatização que ocorre no âmbito da singularidade. Com efeito, se indaga: "Se o dinheiro é o vínculo que me liga à vida humana, que liga a sociedade a mim, que me liga à natureza e ao homem, não é o dinheiro o vínculo de todos os vínculos?" ${ }^{\prime 6} \mathrm{O}$ vínculo que se estabelece através da circulação do dinheiro evidentemente requer e pressupõe que toda uma gama de vínculos realizem-se na sociedade, de diversas ordens. O dinheiro, contudo, possui como atributos uma universalidade concreta e uma onipotência abstrata, operando continuamente trocas e fluxos de propriedades, qualidades e experiências, atreladas a relação entre a vida e as mercadorias. Marx observa que

O dinheiro - enquanto exterior, não oriundo do homem enquanto homem, nem da sociedade enquanto sociedade -, meio e capacidade universais, faz da representação efetividade e da efetividade uma pura representação, transforma igualmente as forças essenciais humanas efetivas e naturais em puras representações abstratas (...). Já segundo esta determinação o dinheiro é, portanto, a inversão universal das individualidades, que ele converte no seu contrário (....). ${ }^{7}$

Operando essa inversão, o dinheiro apropria-se de algum modo das singularidades e faz com que elas se movimentem na procura constante de que através do dinheiro realizem a troca de sua força representativa de valor em relações e propriedades efetivas - de uma maneira geral, em posse. O poder que o dinheiro exerce sobre as vidas humana é o transformar-se, para elas, em posse, por cuja mediação tacitamente o poder apropria-se em contrapartida do seu ser mesmo. dinheiro realiza a conversão do ser em poder. Qual, porém, é o sentido desse poder já vimos antes: realizar o fluxo contínuo do capital e, com isso, introjetar na vida concreta e anímica da sociedade a subjetividade automática da produção de valor. Sob essa apropriação por meio do dinheiro, o fluxo de capital transmuda-se no

MARX, Karl. Manuscritos econômico-filosóficos, p. 159.

MARX, Karl. Manuscritos econômico-filosóficos, p. 160. 
processo que confere vida ao metabolismo social, circulando livremente pelas suas infinitas células, em tudo aquilo que acontece com elas e o que elas fazem acontecer. Esse processo é o grande acontecimento sutil e devastador que entremeia todas as coisas, mas cujo poder parece transcendê-las. E se o valor é a alma do metabolismo social, o dinheiro é essa espécie de união hipostática entre a produção de valor e o corpo social.

E o que, então, tem a ver essas reflexões sobre Marx com o fenômeno global da sociedade em rede? Certamente não conseguiremos senão muito mal esboçar algumas vias para possíveis respostas. O próprio Deleuze no Post-Scriptum... frisa que a sociedade de controle é, além de um novo regime de dominação, uma mutação do capitalismo; se o é de fato, requer de nossa parte desmistificarmos a empolgação desarrazoada com a internet em seus potenciais de democratização (que não são desprezíveis e nem menos revolucionários). Precisamos, então, problematizarmos a internet dentro da conjuntura da lógica capitalista e do processo que ela constitui.

A frase de Žižek "o capital financeiro funciona enquanto noção puramente virtual processando as 'pessoas reais'" 8 pode ser aplicada para a internet. A internet tem a capacidade de, convertendo absolutamente tudo o que trafega dentro dela, em informações, dados e metadados, processar as pessoas reais, transformando seus afetos, gostos, comportamentos, opiniões, expressões etc., em virtualidades. Se a conversão de todas as coisas em informação, operada de maneira remota e descentralizada pela internet, corresponde à essência de nosso admirável mundo novo - no entender de Assange -, então de alguma forma as singularidades todas são apropriadas por essa essência difusa, ramificada e complexa.

A forma como essa apropriação efetiva-se ocorre por meio do que Deleuze cunhou o nome de modulação universal. Esta é o agenciamento específico pelo qual

$8 \quad$ ZIZEK, Slavoj. Menos que nada: Hegel e a sombra do materialismo dialético, p. 92. 
a sociedade de controle se consolida e exerce seu poder - ou, em termos foucaultianos, a modulação universal é o dispositivo de poder disseminado entre as instituições que lutam pelo poder e o administram. A diferença é que essas instituições não são mais físicas, ou melhor, nem tão físicas como muito mais virtuais e, com isso, descentralizadas e ramificadas pelas múltiplas e simultâneas conexões que atravessam e captam a rede, a fim de armazenar as informações como forma de acumulação de capital biopolítico, passível de ser transformado em investimentos e especulação financeira. Em resumo, em produção imaterial de mais-valor. O que o dinheiro representava nos tempos de Marx em termos de tomada de posse sobre as individualidades, no momento atual a internet representa para a multidão - só que de forma exponencialmente potencializada e ampliada, uma vez que a natureza infográfica da web insere-se profundamente no processo de formação das subjetividades contemporâneas, estendendo-se como a modulação - o molde em malha, em rede - pela qual elas se constituem. O alto preço pago dessa autoconstituição em rede por parte da multidão é ter de carregar a moratória ilimitada de sua dívida para com o controle que ela mesma auxilia em replicar e disseminar. Da mesma forma como esse processo já era operado pela circulação do dinheiro independente das decisões e alheio às vontades singulares, ocorre com o controle que universalmente espalha-se pela multidão. Até mesmo a natureza física do dinheiro sofre um gradual desaparecimento, confundindo-se com a natureza virtual da informação. O dinheiro, assim como as singularidades, migrou também para o mundo virtual e, por conseguinte, para a internet, entremeando as singularidades com sua capacidade de mediação e conversão em ampliações de possibilidades, inclusive de potencializar acessos e conexões.

O dinheiro operava sob a modelagem das possibilidades de representação; já a internet rompe os distanciamentos e a universalidade abstrata próprias de um 
sistema de representação. Não há mais, no mundo virtual, separação entre vida e representação: o mundo da vida, no ciberespaço, na imanência informacional realiza o fluxo e o intercâmbio constantes entre o fora e o dentro, esse mundo da vida tende a permear a realidade por inteiro.

Além de elucidarmos e refletirmos sobre a arquitetura de dominação inerente às estruturas físicas da internet, as quais, de antemão, podem minar quaisquer perspectivas revolucionárias de ações contra os poderes governamentais, corporativos e financeiros, precisamos afinal mergulhar nas malhas que envolvem esse processo e que, com ele, irradiam uma forma de acumulação e reprodução de poder para além de quaisquer medidas e que por sua dinamicidade mesmo possui uma vida própria. Necessitamos pensar se a internet é realmente instrumento de emancipação do capital ou se, ao contrário, faz parte de sua radical mutação, de fazer assomar novas formas ramificadas e disseminadas de controle e mediação, sob as quais a lógica interna do capital se autoconstitui como sujeito automático processo de produção do sociometabolismo do mundo contemporâneo.

Independente das origens e do uso que se faz da internet, a capacidade da produção de valor exercer a função retroativa e mediadora de causalidade remota e absoluta da sociedade nos conduz a reflexão sobre se a vigilância das instituições de poder não são "apenas" expressões da reprodutibilidade e capacidade de adaptação do capital. Com isso estaríamos determinados pela sua macro e ao mesmo tempo invisível inexorabilidade? Por detrás de todos os acontecimentos na vida contemporânea, ele é o evento do universal que se instala e se dilui por meio das singularidades e multiplicidades, fazendo-as funcionar virtual e metaestavelmente para a manutenção de sua lógica imanente? Seria, enfim, a interface da rede uma outra máscara do capital? Máscara que personifica e opera a sua complexa subjetividade maquinária? 


\section{Referências bibliográficas}

ASSANGE, Julian. "Um chamado à luta criptográfica". In: APPELBAUM, Jacob; ASSANGE, Julian; MÜLler-MAGUHN, Andy; ZIMMERMANN, Jeremy. Cypherpunks: liberdade e o futuro da internet. São Paulo: Boitempo Editorial, 2013.

DELEUZE, Gilles. "Post-Scriptum sobre as sociedades de controle". In:

Conversações. Trad. Peter Pál Pelbart. São Paulo: Ed. 34, 1992, p. 219-226.

MARX, Karl. Manuscritos econômico-filosóficos. Trad. Jesus Ranieri. São Paulo: Boitempo Editorial, 2008.

O capital: livro I. Trad. Rubens Enderle. São Paulo: Boitempo Editorial, 2013.

ŽIŽEK, Slavoj. Menos que nada: Hegel e a sombra do materialismo dialético. São Paulo: Boitempo Editorial, 2012. 